\title{
Teledermatology: First Steps in Ukraine in the Light of Contemporary World Achievements
}

\section{Korolenko VV'1,2* and Stepanenko $\mathbf{V I}^{2}$}

${ }^{1}$ Department of Health, Kyiv Regional State Administration, Kyiv, Ukraine

${ }^{2}$ Department of Dermatology and Venereology, National O.O Bogomolets Medical University, Kyiv, Ukraine

\begin{abstract}
Two major problems of the contemporary health services of every country are necessary to be decided are low quality of health care and unequal access to health services. One way to solve this problem is to develop such contemporary direction as telemedicine. Telemedicine is a method of providing health care services, where distance is a critical factor. Services by representative of all medical specialties using information and communications technology after receiving information required for diagnosis, treatment and prevention of disease.
\end{abstract}

In teledermatology telecommunications technology are used to share medical information (for skin diseases and skin tumors) at a distance using audio, video and data transmission. Many projects of teledermatology are implemented throughout the world. One promising project is dedicated to the early detection of skin cancers in New Zealand. Experience of some countries, including Ukraine and Malta, shows that methods of telemedicine may be promising in the project "Euromelanoma."

Teledermatology is a very promising branch of medicine. Figuratively speaking, we are scratching the surface only at present. Certainly, its further development will improve the quality and accessibility of health care, especially in remote from the centers of the regions, throughout the world.

Keywords: Telemedicine; Teledermatology; Public health; ehealth

\section{Introduction}

Two major problems of the contemporary health service of Ukraine to be solved are low quality of health care and unequal access to health services [1].

The main objective of the improving the health sector is to ensure equal and fair access of all citizens to health care of appropriate quality. To achieve this, the following tasks are put :

- to improve the quality of medical services;

- to increase access to health services;

- to improve the effectiveness of public funding;

- to create incentives for healthy living and healthy working conditions.

The greatest difficulties in solving these problems arise to assist the population living in rural areas, due to low income of the vast majority of peasants, territorial remoteness of villages from secondary and tertiary health care levels and poor transport communications of rural communities with large cities and metropolitan areas, which focused technical and personnel potential of the health system. In this situation, high-quality, timely, qualified medical assistance is not available for the majority of the population living in rural areas. This problem is very crucial in dermatology, especially in cases of early diagnosis of skin cancer. It leads to late coverage of patients by qualified medical care, to tips and advice neglect of primary care physicians to obtain timely advice of doctors - specialists and, in result, leads to deterioration in health, growth of chronic diseases and reduced life expectancy $[2,3]$.

One way to solve this problem is to develop such contemporary direction as telemedicine. Telemedicine, as defined by the "Regulations on the interaction of telemedicine centers and health care facilities," approved by Order of the Ministry of Health of Ukraine No.261 of March 23, 2010 "On the introduction of telemedicine in health care" is a method of providing health care services, where distance is a critical factor. Services by representative of all medical specialties using ICT after receiving information required for diagnosis, treatment and prevention of disease.

According to the guidelines "Model to improve the availability and quality of health care for the rural population with the use of telemedicine technology ", developed in 2012 by Ukrainian authors (O.P. Mintser et al.), telemedicine can follow such practical problems of public health care management as:

- Up to date to ensure adequate medical, preventive and health needs and demands of citizens;

- Continually improve skills of the industry, and as a result, improve the efficiency of medical care (improving clinical, social and economic outcomes, epidemiological situation, storage and disaster recovery, etc.);

- to improve objective quality of health care, to decrease morbidity, improve demographics, work of medical institutions, etc., to obtain positive social - demographic effects (quality of life), to optimize financial management sector, etc. [2]

For the first time the term "telemedicine" (or rather "telemedical technique") applied R.L. Murphy and colleagues (1970) [4], and two years later - K.T. Bird (1972) - to determine the use as a communication tool TV services - the so-called two-way or interactive, television [5]. In 1974 R.G. Mark has published a great article, which proved telemedicine as a system for approximation of tertiary health care to

*Corresponding author: Volodymyr Korolenko, Department of Health, Kyiv Regional State Administration, Kyiv, Ukraine, Tel: +380444841591; E-mail: v_korolenko@yahoo.com

Received August 22, 2014; Accepted September 11, 2014; Published Septembe 13,2014

Citation: Korolenko VV, Stepanenko VI (2014) Teledermatology: First Steps in Ukraine in the Light of Contemporary World Achievements. Pigmentary Disorders 1:131. doi:10.4172/JPD.1000131

Copyright: (C) 2014 Korolenko VV, et al. the terms of the Creative Commons Attribution License, which permits unrestricted use, distribution, and reproduction in any medium, provided the original author and source are credited. 
every house [6]. Nowadays telemedicine works effectively in the UK, USA, Canada, Scandinavian countries, Australia, New Zealand and Japan [7].

World Health Organization (WHO) has repeatedly published documents relating to various processes of medical information. However, the most profound and important of these is the Report by the WHO Secretariat A58/21 "eHealth", in which clearly benefits, the possibilities and directions of further information are defined. In particular, the resolution states: "eHealth should have an impact on health systems by making health services more efficient and improving access to care, especially in remote areas, for people with disabilities and for the elderly. It should benefit health-care providers, professionals, and final users through higher quality of care and health promotion. It should also affect the cost of care by reducing redundancy and duplication of examinations and making possible economies of scale. ...The strengthening of health systems through eHealth may contribute to the enjoyment of fundamental human rights by improving equity, solidarity, quality of life and quality of care". Thus, eHealth "...understood in this context to mean use of information and communication technologies locally and at a distance". Based on this report, the World Health Assembly adopted resolution WHA58.28 "eHealth" (25 May 2005) [8].

Teledermatology is a subspeciality in dermatology, which is probably one of the most common uses of telemedicine and eHealth. In teledermatology telecommunications technology are used to share medical information (for skin diseases and skin tumors) at a distance using audio, video and data transmission. American specialist's dermatologist Perednia D.A. and telemedicist Brown N.A. were the first introduced in the use of the term "teledermatology" in 1995, describing the importance of teledermatological care in rural destitute dermatologists [9].

According Fieleke D.R., Dyer J.A. (2010), teledermatology reduces the waiting period for dermatological consultation [10]. One study showed that while teledermatological consultation by SAF (Store and forward - system of intermediate storage) completed on average 2.17 days (the longest way teleconsultation), then waiting for admission to University Hospital on average lasts 90 days and for consultation in a local clinic 17.18 days [11]. Teledermatology also reduces the intervention. When assistance is provided by the mechanism of SAF, the necessary measures were completed on average 41 days, and if standard procedures referral for 127 days (this term refers to the British model of building dermatological services borrowed the American health care system) $[12,13]$. Also teledermatology proved very effective method of sorting, eliminating $31 \%$ of clinic visits using the mechanism of SAF $[14,15]$ and up to $72 \%$ with the use of telemedicine in real time [16]. In evaluating patient satisfaction teledermatology interactive, real-time teleconsultation usually perceived as well as "face-to-face" visit to the doctor. Mechanism SAF some patients perceive less likely because of the need video test.

\section{Applications of Teledermatology}

Indications for teledermatology require further research. Some studies indicate that a relatively greater confidence were diagnosed eczema and follicular lesions, while other studies have shown that diagnoses were made with greater confidence in cases of viral warts, shingles, acne, simple contact dermatitis, vitiligo and surface bacterial and fungal infections. Much attention is paid to the early detection of melanoma and other skin cancers. In this regard, experience of teledermatological service of New Zealand is very interesting [17].
Australasian region (Australia, New Zealand, Tasmania and the adjacent part of Oceania) is characterized by the highest, along with the U.S., incidence of melanoma (20-40 cases per 100 thousand population), which is associated, primarily, with the thinning ozone layer over this area. In New Zealand, with a population of 4.4 million people in 20082256 cases of melanoma (the fourth most common type of cancer after cancer of the colon, breast and prostate), and 317 deaths as a result were registered. Expenses for the management of patients with melanoma in New Zealand, it is estimated that at least 57 million NZ dollars in 2006 (value 1 American dollar: 1 New Zealand dollar is approximately 1:1,2) also registered annually about 67,000 new cases of non-melanoma skin malignancies.

Important role in the diagnosis and treatment of both melanoma and non-melanoma skin malignancies play dermatologists. However, access to a dermatologist in New Zealand is limited to lack of doctors of this specialty (1 per 77000 population), as New Zealand Dermatological service based on the British model [6]. Numerous studies have shown that general practitioners and surgeons are less able to achieve diagnostic accuracy than dermatologists in the early diagnosis of malignant tumors of the skin. The way out of this situation may be bringing telemedicine. For this purpose, at the Department of Dermatology at Waikato Hospital in Hamilton at the expense of the Department of Health Waikato region created a skin virtual lesion clinic (VLC). The study was conducted as part of the initiative of the Government of New Zealand "Primary health care" Better, Sooner, More Convenient, "designed to bring high-quality qualified secondary health care in the home for each patient [18].

VLC Patients were invited to visit a local clinic, located $2 \mathrm{~km}$ from the hospital. Specially trained nurses (melanographers) received their informed consent and completed a standardized medical history. Using a specially adapted camera, received regional and macroscopic images dermoscopical skin lesions, which are then downloaded to a secure server.

Each case is considered remotely one of two experienced teledermatologist. Assessment is usually carried out within 24 hours. When possible, it was diagnosed and further tactics planned. Among the options tactics were making repeated imaging for follow-up or referral for treatment. Such treatment could be provided with general practitioners, nurse dermatological clinic dermatologist or plastic surgeon hospital. When the diagnosis was impossible to determine patient received traditional consultation appointment at the clinic.

The same time a similar group of patients was surveying with the principle of classical consultations FTF (face-to-face), which was performed in dermatological clinics in the direction of a general practitioner.

After the research surveys of patients and their general practitioners in VLC and FTF groups about the waiting time, convenience and privacy research were conducted. Also performed financial analysis to determine the economic feasibility teledermatology compared with classical advice.

The results showed that in $88 \%$ of patients do not need to attend a specialized clinic for dermatological diagnosis. Latency results reduced, enabling early surgical intervention in such serious diseases as melanoma. Because patients often have to travel long distances to see a dermatologist on a "face-to-face", creating teledermoscopical clinics in rural communities will help expand access to expert assistance, and reducing transport costs and waiting time of patients. Clinical pictures often included in telemedicine practice, but in the absence of 
dermoscopical images are often insufficient for diagnosis.

Financial analysis showed significant savings in the group VLC. The average cost per case in this group were 264.48 New Zealand dollar vs. 306.48 New Zealand dollar in the group of full-time counseling even excluding transportation costs (saving 14\%) [17].

\section{Ukrainian Experience}

Means of telemedicine and teledermatology are applying now by Ukrainian specialists. Thus, in May 2013 Ukrainian Association of Dermatologists, Venereologists and Cosmetologists in partnership with the Doctor Bogomolets Institute of Dermatology and Representative Office in Ukraine of La Roche-Posay Dermatological Laboratory conducted screening of melanoma in Ukraine under the "Euromelanoma" project (coordinator in Ukraine - Prof. Olga Bogomolets), during which 9648 people were examined, including remotely examination using telediagnostic equipment and IT technologies. Preliminary diagnosis of melanoma is set to 168 , skin cancer - in 352, other malignant neoplasm of skin - to 543 persons [19]. For 2009-2013 during the Day of melanoma in Ukraine 18970 people were viewed, of whom 336 were identified melanoma, 689 skin cancers, 834 pre-cancerous skin tumors.

In the Donetsk region of Ukraine a pilot project implemented for remote consultation dermatological patients in the remote counseling center at the $1^{\text {st }}$ city clinical dermato-venereological dispensary in Donetsk and two subscriber nodes in city dispensaries in Mariupol and Kramatorsk. Work organized by the mechanism of SAF [20]. At present the work of this structure is broken due to the actions of proRussian terrorist groups.

Pursuant to the Order of the Ministry of Health of Ukraine No.261 of March 23, 2010 "On the introduction of telemedicine in health care" in Ukraine, a telemedicine network including the Ministry of Health of Ukraine, State Clinical Research Telemedicine Center in Kyiv, Donetsk and Transcarpathian Regional Hospitals, National M.M. Amosov Institute of Cardiovascular Surgery, the M.O.Semashko Crimean Republican Clinical Hospital was built. Memorandum of Understanding between the Ministry of Health of Ukraine, National Academy of Medical Sciences of Ukraine, "DTEK" Ltd., Charitable Foundation "Development of Ukraine" and private joint stock company "MTS Ukraine" was signed 19 September 2011 for further implementation of telemedicine technology; the draft Law of Ukraine "On telemedicine" was examined in the Supreme Council of Ukraine and now is finalizing.

Thus, Ukrainian teledermatology designed to be a powerful tool to maximize the availability of skilled medical care for Ukrainian and minimize the costs. We consider it appropriate reasonable preservation of the existing network dermatovenereological institutions (dispensaries, departments, offices) superimposed with the functions of subscriber units and remote centers of dermatovenereological counseling according to the level of the institution. The most appropriate telemedical mechanism, given the predominantly visual nature of the primary physical diagnosis in dermatology, is consulting in real time, followed by an optional teledermatopathology. For the purpose of screening for malignant tumors of the skin it is appropriate wide teledermoscopy involving trained experts in this type of diagnosis. Implementation of teledermatology in Ukrainian Health practice will provide a significant (40\%) savings to pay for health care services, improve efficiency and accessibility (temporal and spatial) of dermatological care for every inhabitant of Ukraine.

\section{Conclusion}

Teledermatology is a very promising branch of medicine. Figuratively speaking, we are scratching the surface only at present. Certainly, its further development will improve the quality and accessibility of health care, especially in remote from the centers of the regions, throughout the world. In Ukraine still lacks a single piece of legislation that would regulate telemedicine. Draft Law of Ukraine "On telemedicine" was held in 2012 in the expert committee of the Supreme Council of Ukraine and withdrawn for revision.

Among the legal issues of teledermatologic primary care is privacy, in particular, the issue of medical confidentiality in the provision of telemedicine. In teledermatology it's particularly important because dermatovenereologists deal with cases of STIs and skin diseases, many of which are causing psychological discomfort and social exclusion. According to the Law of Ukraine "On Information" confidential information can be distributed as desired (consent) the person specified by it in accordance with the procedure provided for her condition, and in other cases stipulated by law. In addition, the provision of telemedicine is also governed by the Law of Ukraine "On protection of information in computer systems." An important prerequisite to the creation of the national telemedicine legal framework was the adoption of the Law of Ukraine "On electronic documents and electronic document" and "On electronic digital signature". The introduction of electronic document management in health care is one of the priorities under the National Action Plan for 2012 and 2013 implementation of the program of economic reforms for 2010-2014.

Appropriate and relevant is to pass a special law of Ukraine "On telemedicine" and relevant regulations. Of course, this should be preceded by research to identify relevant legal issues related to telemedecal activities and develop options to address them. This will give new impetus to the development of the teledermatology as well as one of the most common practical applications of telemedicine.

\section{Acknowledgment}

The authors would like to express their sincere appreciation to Prof. J. L. Pace (Malta) and to Prof. O.V. Bogomolets (Ukraine) for kindly provided information and advice.

\section{References}

1. Engaging for Health(2006) 11th General Programme of Work, 2006-2015. A Global Health Agenda. World Health Academy.

2. Mintser OP, Tsarenko AV, Matyukha LF (2012) Model to improve the accessibility and quality of health care for the rural population with the use of telemedicine technology (guidelines) Kyiv. Ukrainian.

3. Popchenko TP (2012) Regarding the current status and future directions for the financing and management of health care in Ukraine. Policy Brief of the National Institute for Strategic Studies under the President of Ukraine.

4. Murphy RL, Barber D, Broadhurst A, Bird KT (1970) Microwave transmission of chest roentgenograms. Am Rev Respir Dis 102: 771-777.

5. Bird KT (1972) Cardiopulmonary frontiers: quality health care via interactive television. Chest 61: 204-205.

6. Mark RG (1974) Telemedicine system: the missing link between homes and hospitals? Mod Nurs Home 32: 39-42.

7. Zundel KM (1996) Telemedicine: history, applications, and impact on librarianship. Bull Med Libr Assoc 84: 71-79.

8. eHealth (2005) Report by the Secretariat. World Health Organization. Fiftyeighth World Health Assembly.

9. Perednia DA, Brown NA (1995) Teledermatology: one application of telemedicine. Bull Med Libr Assoc 83: 42-47.

10. Fieleke DR, Dyer JA (2010) Teledermatology in Pediatric Dermatology - An Overview of Current Status and Future Potential. US Dermatology 4: 62-64. 
11. Krupinski E, Barker G, Rodriguez G, Engstrom M, Levine N, et al. (2002) Telemedicine versus in-person dermatology referrals: an analysis of case complexity. Telemed J E Health 8: 143-147.

12. Stepanenko V, Korolenko VV (2012) Structure of dermatological and venereological care system in the leading countries of the world in terms of the prospects for reform of dermato-venereological services in Ukraine. Ukrainian Journal of Dermatology, Venereology, Cosmetology 4: 19-24.

13. Whited JD, Hall RP, Foy ME, Marbrey LE, Grambow SC, et al. (2002) Teledermatology's impact on time to intervention among referrals to a dermatology consult service. Telemed J E Health 8: 313-321.

14. Loane MA, Bloomer SE, Corbett R, Eedy DJ, Hicks N, et al. (2000) A comparison of real-time and store-and-forward teledermatology: a cost-benefit study. Br J Dermatol 143: 1241-1247.

15. Taylor P, Goldsmith P, Murray K, Harris D, Barkley A (2001) Evaluating a telemedicine system to assist in the management of dermatology referrals. $\mathrm{Br}$ J Dermatol 144: 328-333.
16. Lamminen $\mathrm{H}$, Tuomi ML, Lamminen J, Uusitalo $\mathrm{H}$ (2000) A feasibility study of realtime teledermatology in Finland. J Telemed Telecare 6: 102-107.

17. Lim D, Oakley AM, Rademaker M (2012) Better, sooner, more convenient: a successful teledermoscopy service. Australas J Dermatol 53: 22-25.

18. 'Better, Sooner, More Convenient' Primary Health Care. New Zealand Ministry of Health, Primary Health Care.

19. Stepanenko V (2013) Day for diagnosis of melanoma. Official UADVC information. Ukrainian Journal of Dermatology, Venereology, Cosmetology 2 : $12-13$

20. Kutsenko IV (2004) Using information technology to provide dermatological care to residents of Donetsk. Ukrainian Journal of Telemedicine and Medical telematics 2: 80-84. 